\title{
Perancangan Aplikasi Timbangan Bayi pada Posyandu dengan Standar Antropometri WHO 2005 Menggunakan Arduino Uno R3, Ms.Visual Studio. Net 2010 dan MySQL
}

\author{
Noviardi $^{1}$, Alfin Aperta ${ }^{2}$ \\ ${ }^{1,2}$ Teknik Komputer, Sekolah Tinggi Teknologi Payakumbuh, \\ J1.Khatib Sulaiman Sawah Padang Telp (0752) 7010851 Fax (0752) 90063 Payakumbuh \\ maha_rajo@yahoo.co.id ${ }_{2}^{1}$ alfinaperta@gmail.com ${ }^{2}$
}

\begin{abstract}
Abstrak - Standar Antropometri tahun 2005 yang di terbitkan oleh World Healt Organization (WHO) telah digunakan untuk menilai status gizi anak di indonesia. Penilaian staus gizi anak dimulai dari Posyandu (Pos Pelayanan Terpadu) merupakan pelaksana dilapangan yang secara langsung mengumpulkan, penganalisis status gizi bayi dengan menghitung Umur, mengukur Panjang Badan (PB) dan Tinggi Badan (TB). Proses pengumpulan dan analisis data pengukuran membutuhkan banyak waktu dan ketelitian yang tinggi supaya diperoleh hasil yang akurat, efisien dan efektif. Untuk itu dibutuhkan inovasi dalam merancang alat ukur menggunakan teknologi portable mikrokontroler Arduino Uno R3 yang di kolaborasikan dengan Aplikasi Visual Studio. 2012 pengolah data dan MySql sebagai penyimpanan data.
\end{abstract}

Kata Kunci - Alat ukur tinggi badan/panjang badan, alat ukur berat badan, Antropometri, Arduino, Mikrokontroller, Ms. Visual Studio 2010, MYSQL, Status gizi, WHO

\section{PENDAHULUAN}

Antropometri berasal dari kata antropos yang artinya tubuh dan metros yang berarti ukuran. Berat badan merupakan ukuran antropometri yang terpenting dan paling sering digunakan pada bayi yang baru lahir (neonatus). Berat badan digunakan untuk mendiagnosa bayi normal atau BBLR. Dikatakan BBLR apabila berat bayi-balita yang lahir dibawah 2500 gram atau dibawah $2,5 \mathrm{~kg}$. Sedangkan tinggi badan merupakan antropometri yang menggambarkan keadaan pertumbuhan skeletal. Pengukuran tinggi badan digunakan untuk menilai status perbaikan gizi bayi. Pengukuran bayi dapat dilakukan di rumah sakit, puskesmas, posyandu atau diklinik bersalin.

Saat ini diposyandu untuk menentukan gizi bayi didapat dari berat dan tinggi badan bayi masih secara manual. Yaitunya pengambilan data berat dan tinggi badan bayi yang diisikan terkadang tidak sama dengan data berat dan tinggi badan bayi yang aslinya, maka dari itu perancangan berat dan tinggi badan bayi untuk menghitung status gizi yang pas membutuhkan metode yang baru.

Dalam perancangan berat dan tinggi badan bayi menggunakan timbangan terintegrasi dengan alat ukur tinggi badan untuk mendapatkan gizi bayi, dibutuhkan metode baru dalam pembuatan dan pengisian datanya. Sehingga data yang dibuat lebih akurat dan mendekati data yang aslinya, memudahkan pencarian data yang telah diisi sebelumnya. Oleh karena itu perancangan alat timbangan ini berguna untuk mendapatkan status gizi bayi berdasarkan Standar Antropemthry yang diterbitkan oleh World Healt Organization (WHO) dengan menggunakan arduino uno sebagai mikrokontroler yang akan membaca nilai Output dari sensor, yang dilengkapi dengan Ms Visual Studio sebagai pengolahan data yang nantinya akan disimpan pada database.

Penggunaan database sangat penting dalam perancangan timbangan bayi, dengan menggunakan database kita dapat menyimpan data dan dapat memanggil kembali data yang telah disimpan sebelumnya. Sehingga saat data dibutuhkan kembali, kita dapat mengambil data yang kita butuhkan yang telah tersimpan didala database. Dalam pengolahan database nantinya akan digunakan Ms. Visual Studio sebagai pengolahan dan penginputan data yang nantinya akan disimpan kedalam database.

Mikrokontroler adalah sebuah system komputer yang seluruh atau sebagian besar elemennya dikemas dalam satu chip IC, sehingga sering disebut single chip microcomputer (Chamim 2010) [1], memiliki beberapa keluaran dan masukan yang digunakan untuk melakukan komunikasi timbal balik dengan dunia luar berupa sensor dan aktuator (Jatmika 2011).

Arduino adalah salah satu keluarga Atmel mikrokontroler yang menggunakan chip Atmega 328 yang menggunakan bahasa $\mathrm{C}$ sebagai program pengontrolan (Julien Bayle 2013) yang dikembangkan dengan menggabungkan beberapa fungsi pemrograman yang komplek kepada perintahperintah yang sederhana (simple command)(Mike, 2012) 
Arduino dapat bekerja bila dihubungkan dengan USB ke komputer yang digunakan sebagai sambungan untuk mendownload skecth yang telah di buat, karena arduino telah dilengkapi dengan port USB.

(Noviardi 2016) menjelaskan bahwa untuk menghubungkan arduino dengan perangkat lain (devices) dapat menggunakan jalur komunikasi transmited dan received, dengan model komponen sebagai berikut :

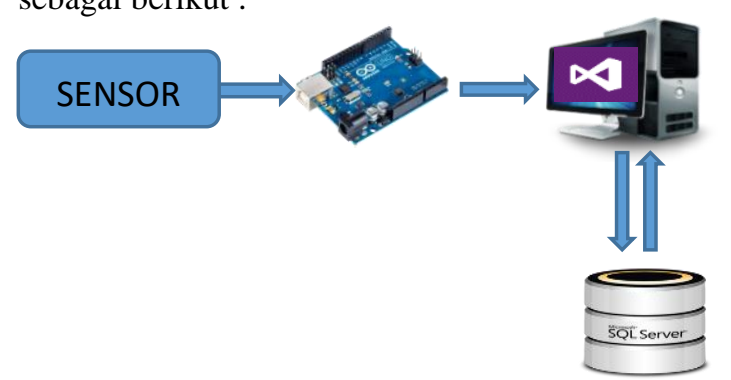

a) Transmitted

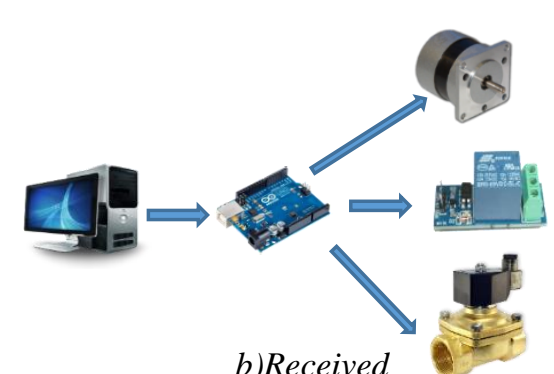

Gambar 1 Komponen Model

sebagai suatu kesatuan sistem (Jusak 2013). Sensor pada sebuah device digunakan untuk mengambil informasi dan data yang dibutuhkan. Selanjutnya, Aliran data dalam sistem mengikuti aliran (cycle) yang dimulai dari memproduksi data dan pengumpulan data, transfer, penyaringan dan pemrosesan, penyimpanan dan pengarsipan (AbuElkheir et al, 2013). Aliran data yang terkonsentrasi dalam databese berupa informasi-informasi yang telah diolah dari hasil perolehan sensor (Robles et al. 2015). Data disimpan dalam database server yang dapat diakses oleh user secara realtime (Seminar 2011).

\section{METODOLOGI PENELITIAN}

Penelitian ini bertujuan untuk menghasilkan produk yang dimanfaatkan oleh dinas kesehatan, produk yang akan didesain berupa timbangan berat dan tinggi badan pada bayi dengan sistem elektronik yang dapat digunakankan oleh posyandu. Untuk itu penelitian ini diselesaikan dengan menggunakan metode research and development (R\&D). Menurut Sugiono (2009) "metode penelitian dan pengembangan adalah metode penelitian yang digunakan untuk menghasilkan produk tertentu dan menguji ke efektifan produk tersebut". Penelitian dan pengembangan adalah suatu proses atau langkahlangkah mengembangkan produk baru atau menyempurnakan produk yang telah ada (Rohman 2013).

Dalam perancangan software digunakan metode System Development Life Cycle (SDLC), System Development Life Cycle (SDLC) atau dalam bahasa Indonesia disebut Siklus Hidup Pengembangan Sistem adalah istilah yang digunakan untuk menjelaskan proses dalam pengembangan Sistem Informasi (Richie, 2014). SDLC digunakan untuk merencanakan, menciptakan, dan pengujian serta pengembangan Sistem Informasi. Secara umum SDLC terdiri atas tahapan pekerjaan yang digunakan oleh pengembang sistem untuk merancang, mendesain, membangun, serta menguji sistem informasi. Konsep dari SDLC itu sendiri dapat mencakup pengaturan dari hardware dan software, suatu sistem dapat diterapkan untuk hardware atau software saja, atau dapat merupakan kombinasi dari keduanya. Tahapan dalam SDLC adalah 1) Perencanaan, 2) Analisis, 3) Desain, 4) Penerapan, 5) Pasca Impelementasi (Perawatan). Untuk lebih jelasnya dapat dilihap pada gambar berikut :

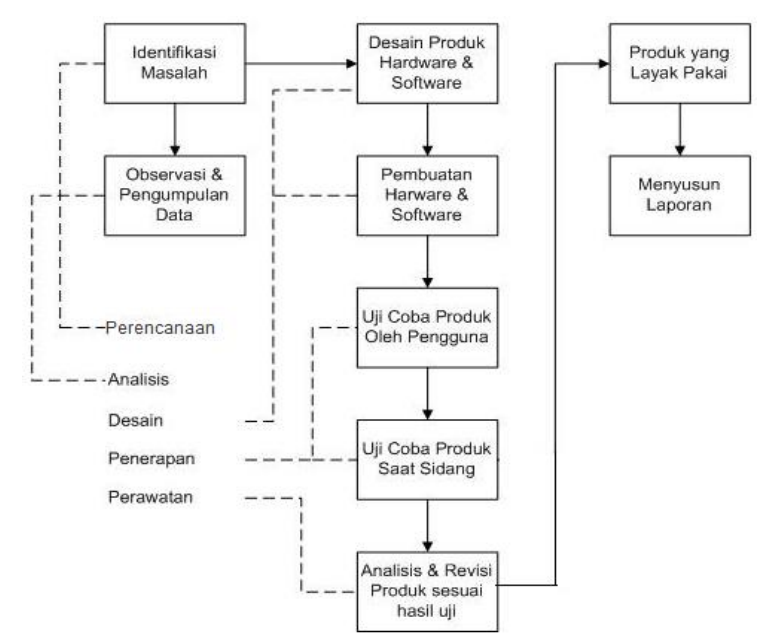

Gambar 2. Tahapan SDLC

Sebelum membahas perencanaan rancangan yang akan dibuat, ada beberapa langkah umum yang akan dilakukan dalam melakukan penelitiaan ini. Langkah awal dalam penelitian ini adalah mempelajari kerja dari sistem secara utuh dan terinci termasuk memahami teori yang mendasarinya, selanjutnya melakukan perancangan sistem (berupa simulasi dengan menggunakan 
software "ISIS Proteus 7 Profesional"), Berdasarkan kinerja komponen dengan mempertimbangkan faktor kesesuiaan komponen dalam sistem, pengujian dari setiap kompoen hardware, perancangan dan pemograman software (perangkat lunak), dan terakhir adalah penyusunan laporan.

\section{HASIL DAN PEMBAHASAN}

Pada bab ini membahas tentang kinerja Perancangan timbangan bayi pada posyandu menggunakan arduino uno R3, Ms.Visual Studio 2010 dan MySql. Untuk pembuatan rancangan alat timbangan bayi yang telah dikerjakan mulai dari perancangan hingga uji fungsi. Adapun persiapan yang dilakukan meliputi alat dan bahan, pemaparan hasil - hasil dan pendataan pada setiap rangkaian yang telah dibuat serta hasil penyempurnaan dalam bentuk tabel. Hal ini bertujuan untuk mendata sejauh mana pengaruh input yang diberikan terhadap kerja sistem.

\section{Rangkaian Resistor Variabel}

Rangkaian resistor variabel berfungsi sebagai pemberi input data dari berat badan yang akan di ukur. Rangkaian ini mengubah nilai tegangan input yang di baca oleh mikrokontroller arduino menjadi satuan berat kilogram, pada rangkaian ini digunakan resistro variabel berjenis slider dengan impedensi $100 \mathrm{Kohm}$. Pada rangkaian ini diberi input sebesar $5 \mathrm{~V}$ dan output dari resistor variabel di hubungkan ke pin A0 pada arduino. Skema rangkaian resistor variabel dapat dilihat pada gambar dibawah ini :

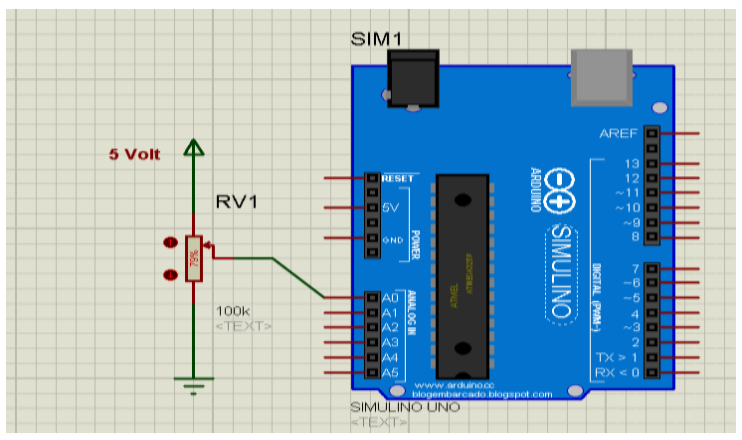

Gambar 3. Skema rangkaian resistor variabel

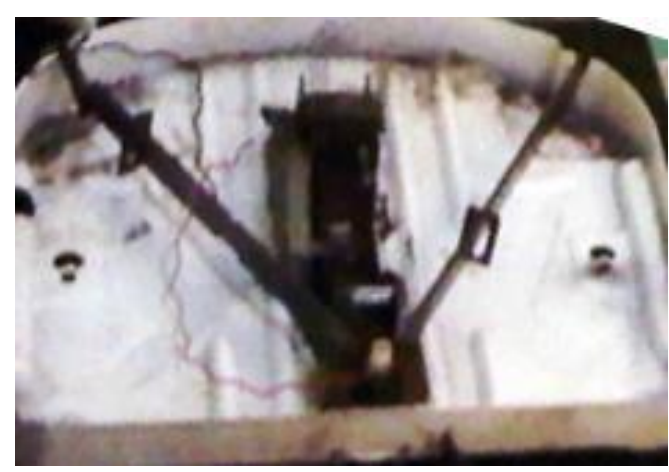

Gambar 4. Rangkaian resistor variabel

\section{Rangkaian Sensor Ultrasonic}

Rangkaian sensor ultrasonic berfungsi sebagai pengukur jarak dari suatu benda yang menghalangi sensor, sensor ultrasonic akan memancarkan sinyal dan akan menerima kembali pantulan dari sinyal tersebut. Waktu dalam peancaran sinyal dan penerimaan sinyal ini kembalilah yang akan di konversikan kedalam satuan jarak. Rangkaian sensor ultrasonic memiliki 4 buah pin, yaitu pin vec, triger, echo dan pin ground, pin vec akan dihubungkan pada pin $5 \mathrm{~V}$ arduino, pin triger sensor di hubungkan pada pin 13 arduino, dan pin echo pada pin 12 arduino. Skema dari rangkaian sensor ultrasonic dapat dilihat pada gambar di bawah ini :

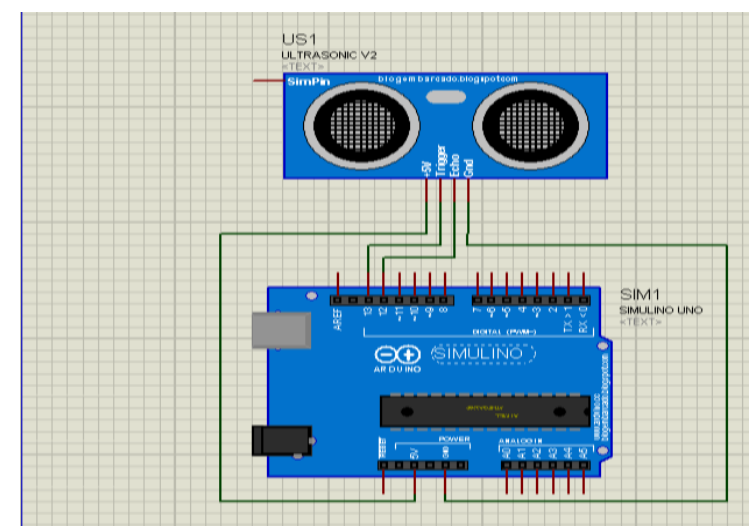

Gambar 5. Skema rangkaian sensor ultrasonic

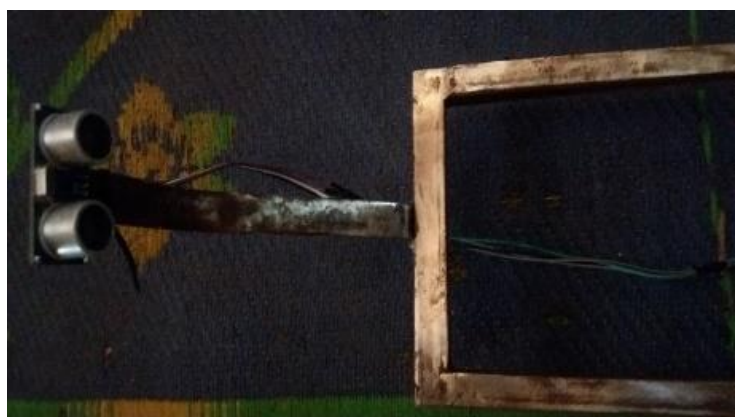

Gambar 6. Rangkaian sensor ultrasonic 


\section{Rangkaian Keseluruhan Alat}

Pada sub bab ini penulis akan menggabungkan keseluruhan rangkaian pada pin arduino, dimana pada pin A0 arduino akan dihubungkan pin pada resistor variabel, sedangkan pada pin 13 akan dihubungkan pada pin trigger sensor ultrasonic, pin 12 di hubungkan pada echo pin sensor ultrasonic. Selanjutnya arduino akan dihubunkan pada PC mengunakan kabel USB. Skema rangkaian keseluruhan dapat dilihat pada gambar dibawah ini :

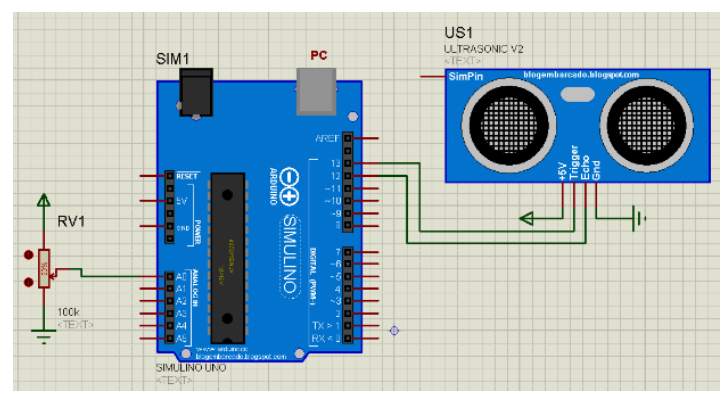

Gambar 7. Skema rangkaian keseluruhan

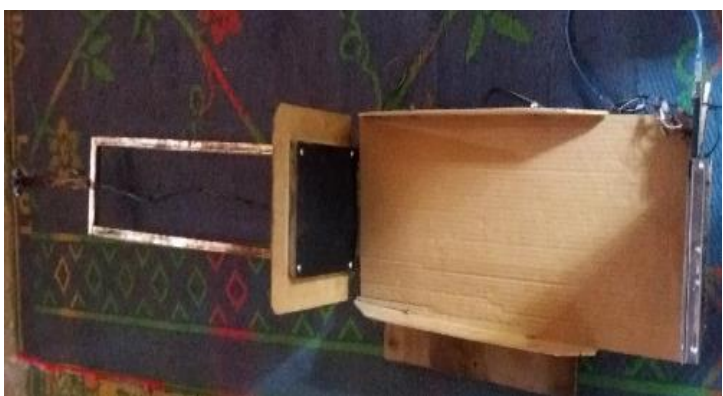

Gambar 8. Rangkaian keseluruhan alat

\section{Hasil Input}

Hasil analisa dan Perancangan timbangan bayi pada posyandu menggunakan arduino uno R3, Ms. Visual Studio 2010 dan MySql, untuk form input dapat dilihat pada berikut :

\section{Form Log In}

Form ini merupakan form log in saat kita menjalankan program. Terlebih dahulu kita menginputkan username dan password yang telah kita sesuaikan dengan data yang terdapat pada tabel login yang ada di database. Bentuk form log in dapat dilihat pada gambar dibawah ini :

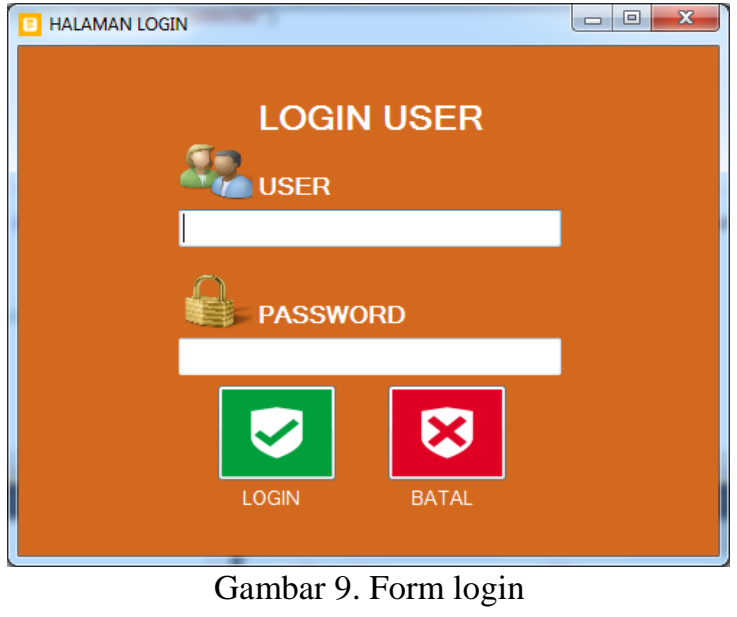

\section{Form Menu Utama}

Form ini digunakan sebagai pemanggil form-form selanjutnya yang digunakan untuk menginput dan memanggil database dari program yang telah dibuat. Bentuk form menu utama seperti terlihat pada gambar dibawah ini :

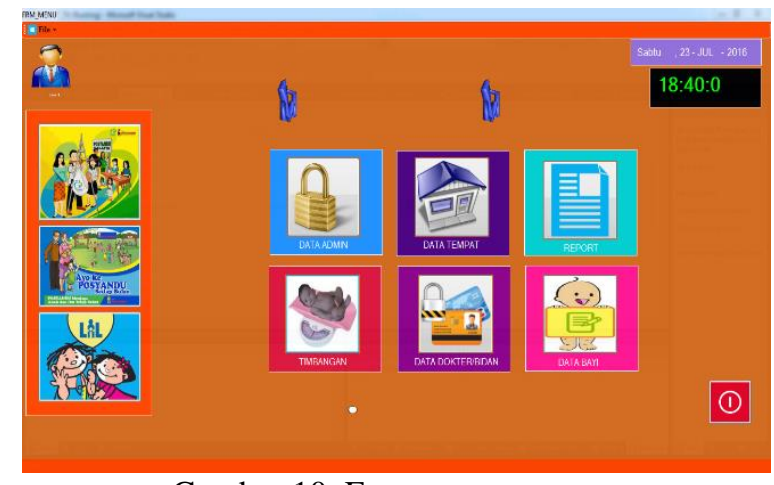

Gambar 10. Form menu utama

\section{Form Input Data Tempat}

Form ini berfungsi menginput, mengedit dan menghapus data daftar dari database yang terlebih dahulu dipanggil dari form menu utama. Bentuk form Input Data Tempat dapat dilihat pada gambar dibawah ini : 


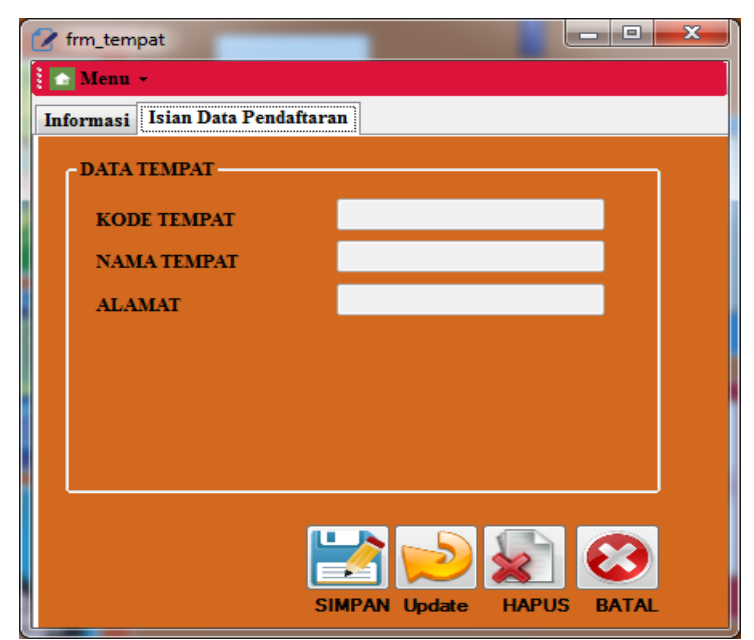

Gambar 11. Form input data tempat

\section{Form Input Data Dokter/Bidan}

Form ini berfungsi menginput, mengedit dan menghapus data daftar dari database yang terlebih dahulu dipanggil dari form menu utama. Bentuk form Input Data Dokter/Bidan dapat dilihat pada gambar dibawah ini :

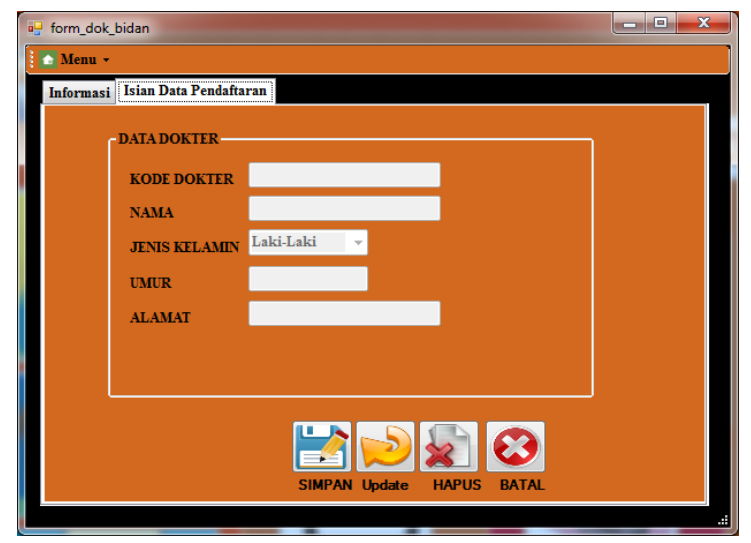

Gambar 12. Form input data dokter/bidan

\section{Form Inputan Data Timbang Bayi}

Form ini berfungsi menginput, mengedit dan menghapus data Timbang Bayi dari database yang terlebih dahulu dipanggil dari form menu utama. Bentuk form data Input Data Timbang Bayi dapat dilihat pada gambar dibawah ini :

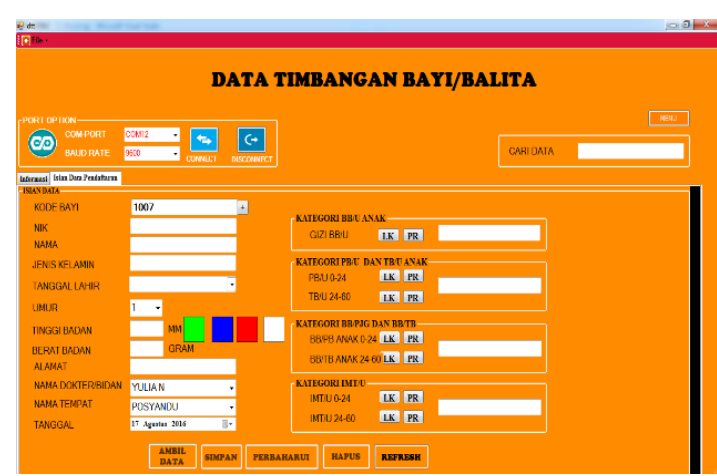

Gambar 13. Form input data timbang bayi

\section{Disain Output}

Hasil Analisa dan Perancangan timbangan bayi pada posyandu menggunakan arduino uno R3, Ms.Visual Studio 2010 dan MySql untuk laporan dapat dilihat pada gambar :

\section{Laporan Data Penimbangan Bayi}

Merupakan tampilan dari Laporan data pendaftaran yang dibuat berdasarkan database yang ada. Bentuk laporan data pendaftaran dapat dilihat pada gambar dibawah ini :

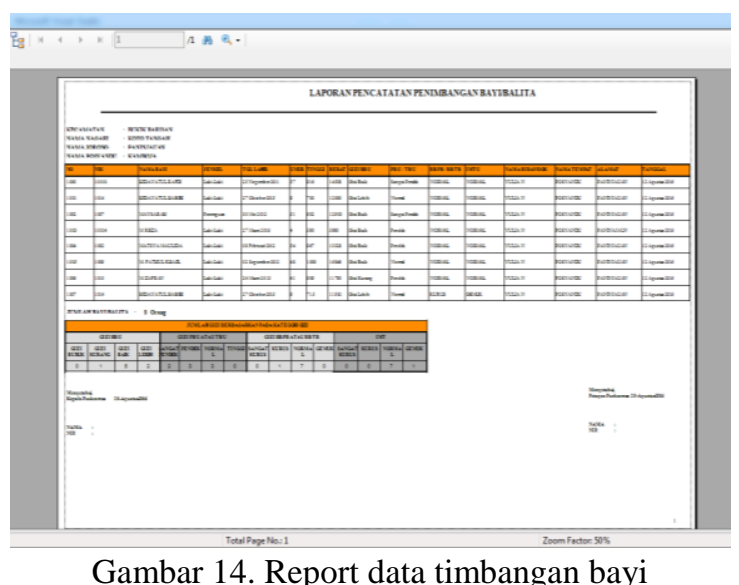

Hasil Data penimbangan manual Posyandu

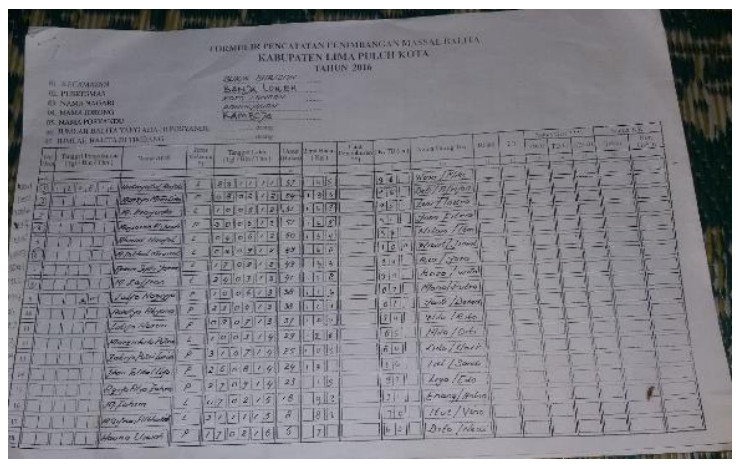

Gambar 15. Data timbang bayi di posyandu 
Hasil penimbangan di Posyandu dilakukan dengan manual, hanya mengisi form yang telah disediakan oleh Dinas Kesehatan.

Hasil Perbandingan Data Timbangan Manual dan elektronik

1. Hasil timbangan berat dan tinggi badan bayi secara manual

\begin{tabular}{l|c|c|c|c|c}
\hline Nama Bayi/Balita & Jenkel & $\begin{array}{c}\text { Tanggal } \\
\text { Lahir }\end{array}$ & $\begin{array}{c}\text { Umur } \\
\text { /Bulan }\end{array}$ & $\begin{array}{c}\text { Berat } \\
\text { Badan/kg }\end{array}$ & $\begin{array}{c}\text { Tinggi } \\
\text { Badan/cm }\end{array}$ \\
\hline HIDAYATUL RAFDI & L & $23-11-2011$ & 57 & 14.5 & 91 \\
\hline MATSYA MAULIDA & P & $08-02-2012$ & 54 & 13.3 & 96 \\
\hline MAYSARAH ALJANAH & P & $30-05-2012$ & 51 & 12.8 & 91 \\
\hline M.FATHUL KHAIRUL & L & $02-09-2010$ & 49 & 16.8 & 100 \\
\hline M.ZAFFRAN & L & $24-03-2013$ & 41 & 11.8 & 90 \\
\hline M.REZA & L & $27-03-2016$ & 5 & 5.9 & 58 \\
\hline HIDAYATUL HABIBI & L & $27-10-2015$ & 10 & 11.9 & 71 \\
\hline
\end{tabular}

Gambar 16. Data Timbang Secara Manual

\section{Hasil timbangan Berat dan tinggi badan} bayi secara elektronik

\begin{tabular}{l|c|c|c|c|c}
\hline Nama Bayi/Balita & Jenkel & $\begin{array}{c}\text { Tanggal } \\
\text { Lahir }\end{array}$ & $\begin{array}{c}\text { Umur } \\
\text { /Bulan }\end{array}$ & $\begin{array}{c}\text { Berat } \\
\text { Badan/kg }\end{array}$ & $\begin{array}{c}\text { Tinggi } \\
\text { Badan/cm }\end{array}$ \\
\hline HIDAYATUL RAFDI & $\mathrm{L}$ & $23-11-2011$ & 57 & 14.5 & 91.6 \\
\hline MATSYA MAULIDA & $\mathrm{P}$ & $08-02-2012$ & 54 & 13.3 & 96.7 \\
\hline MAYSARAH ALJANAH & $\mathrm{P}$ & $30-05-2012$ & 51 & 12.9 & 90.2 \\
\hline M.FATHUL KHAIRUL & $\mathrm{L}$ & $02-09-2010$ & 48 & 16.8 & 100 \\
\hline M.ZAFFRAN & $\mathrm{L}$ & $24-03-2013$ & 41 & 11.7 & 90.9 \\
\hline M.REZA & $\mathrm{L}$ & $27-03-2016$ & 4 & 5.9 & 59 \\
\hline HIDAYATUL HABIBI & $\mathrm{L}$ & $27-10-2015$ & 9 & 12 & 70 \\
\hline
\end{tabular}

Gambar 17. Timbang Secara Elektronik

\section{Grafik Perbandingan Data Timbang Berat Dan Tinggi Badan Pada Bayi}

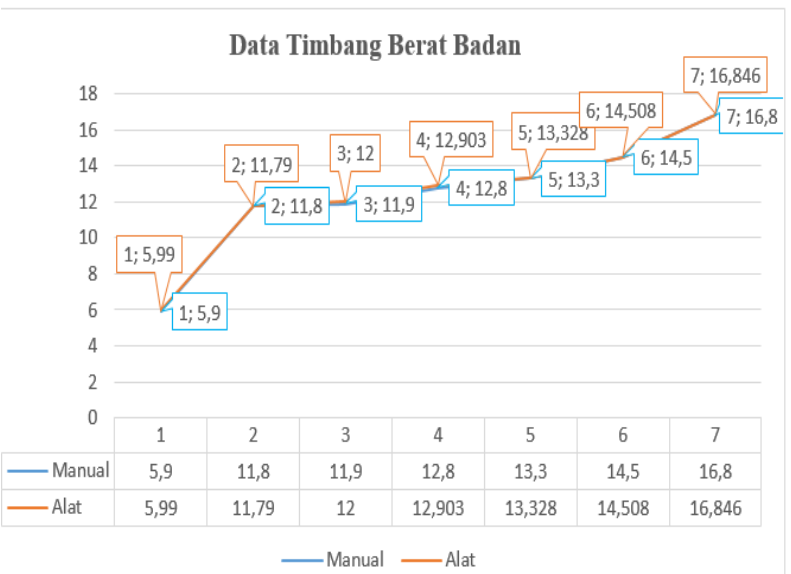

Gambar 18. Grafik perbandingan berat badan secara manual dan elektronik.

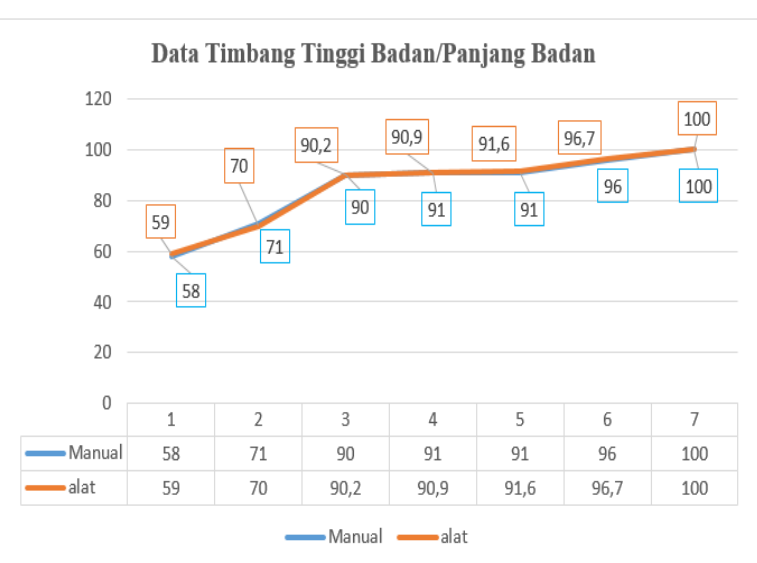

Gambar 19. Grafik perbandingan tinggi badan secara manual dan elektronik

\section{KESIMPULAN DAN SARAN}

Antropometri adalah ilmu yang mempelajari berbagai ukuran tubuh manusia. Dalam bidang ilmu gizi digunakan untuk menilai status gizi. Ukuran yang sering digunakan adalah berat badan dan tinggi badan. Ukuran-ukuran antropometri tersebut bisa berdiri sendiri untuk menentukan status gizi dibanding baku atau berupa indeks dengan membandingkan ukuran lainnya seperti $\mathrm{BB} / \mathrm{U}, \mathrm{PB} / \mathrm{U}$ atau TB/U, BB/PB atau BB/TB, IMT/U

Untuk mencari kategori gizi pada bayi berdasarkan berat badan dan tinggi badan bayi dulunya masih dilakukan secara manual, untuk menangani kelemahan serta kekurangan pada pengolahan data tersebut, maka dirancang sebuah sistem informasi dengan menggunakan bahasa pemrograman VB. NET 2010, dan mikrokontroller arduino dengan tujuan dapat membantu dalam pengolahan data berdasarkan berat badan dan tinggi badan bayi untuk mencari kategori gizi pada bayi tersebut.

Berdasarkan pembahasan dari masing-masing bab, maka dapat disimpulkan bahwa dengan menggunakan bahasa pemrograman dan mikrokontroller arduino sebagai alat pengolahan data berdasarkan $\mathrm{b}$ berat badan dan tinggi badan pada bayi akan memberikan dampak positif antara lain :

1. Dapat mengatasi masalah yang terjadi pada pengolahan data karena menggunakan aplikasi yang dapat menghemat waktu dan tenaga dalam pembuatan laporan.

2. Pengarsipan data lebih teratur, sehingga memudahkan pencarian data jika sewaktuwaktu diperlukan oleh pihak yang berkepentingan serta dapat mengurangi dokumen-dokumen atau arsip berupa lembaran kertas. 
3. Dengan implementasi pemrograman Visual Studio 2010 akan dapat menghasilkan laporan yang sesuai dengan kebutuhan yang diinginkan.

4. Dapat mengurangi human error saat pembacaan data berdasarkan berat badan dan panjang badan/tinggi badan.

5. Dengan menggunakan mikrokontroller akan dapat memudahkan dalam pembacaan nilai hasil ukur berdasarkan berat badan dan panjang badan/tinggi badan.

6. Dapat mengatasi masalah dalam mencari kategori gizi bayi berdasarkan dari alat ukur berat badan dan tinggi badan bayi yang meliputi $\mathrm{BB} / \mathrm{U}, \mathrm{PB} / \mathrm{U}$ atau $\mathrm{TB} / \mathrm{U}, \mathrm{BB} / \mathrm{PB}$ atau BB/TB, IMT/U.

7. Untuk dapat menghasilkan data yang lebih tepat dan akurat pada penimbangan elektronik perlu dilakukan penimbangan berulang-ulang untuk memastikan data hasil timbang itu akurat.

Dengan adanya pergantian sistem pengolahan data yang baru, tentunya akan banyak menimbulkan perubahan. Pada akhir penulisan penelitian ini, maka penulis ingin memberikan saran-saran dengan harapan nantinya dapat bermanfaat dalam pengolahan data berdasarkan berat badan dan panjang badan/tinggi badan untuk mendapatkan hasil ketegori gizi pada bayi.

Adapun saran-saran yang dapat penulis sampaikan adalah untuk menerapkan sistem yang baru untuk pengolahan data berdasarkan berat badan dan panjang badan/tinggi badan untuk mendapatkan hasil ketegori gizi pada bayi perlu dilakukan pelatihan terhadap operatornya agar dapat mengoperasikan program Visual Studio 2010 dengan baik.

Karena komputer mempunyai fungsi ganda sebagai pengolah data dan penyajian informasi, maka dalam pelaksanaannya membutuhkan tenaga yang terampil dan ahli agar aplikasi dapat dijalankan dengan baik.

Dalam melakukan uji coba terhadap sistem yang baru, disarankan sistem yang lama tetap digunakan agar dapat dilakukan perubahan secara bertahap apabila perancangan tersebut belum sesuai dengan sistem yang diharapkan. Sehingga membutuhkan pengembangan lebih lanjut untuk menanggulangi dan mengolah data yang lebih besar di masa yang akan datang.

\section{REFERENSI}

[1] Abu-Elkheir, Mervat, Mohammad Hayajneh, and Najah Abu Ali. 2013. "Data Management for the Internet of Things: Design Primitives and
Solution.” Sensors (Switzerland) 13(11):15582612.

[2] Aperta, Alfin 2016. Perancangan timbangan bayi pada posyandu menggunakan Arduino Uno R3, Ms Visual studio 2010 dan MySql, Tugas Akhir D3 Teknik komputer STT Payakumbuh

[3] Alexander F.K Sibero. 2010. Dasar-dasar VB. NET. Yogyakarta : Mediakom.

[4] Aris Saepul Rohman. 2013. Rancangan Bangun Sistem Pendukung Keputusan Penjurusan Untuk SMA Negeri 1 Subang Dengan Menggunakan Metode Analisis Hierarchy Process Universitas Pendidikan Indonesia Repository.upi.edu Perpustakaan.upi.edu. Bandung. Retrieved (http://repository.upi.edu/3736/6/S_KOM_070 4447_CHAPTER3.pdf).

[5] Betha Sidik, Ir. 2011. MySQL. Bandung : Informatika.

[6] Chamim, Anna Nur Nazilah. 2010. "Penggunaan Microcontoller Sebagai Pendeteksi Posisi Dengan Menggunakan Sinyal GSM." Informatika 4(1):430-39

[7] Dinas Kesehatan Surabaya, Baku Antropometri WHO, 2005

[8] Dodit Suprianto. 2010. Membuat Aplikasi Dekstop Menggunakan MySQL \&danVB. NET Secara Profesional. Malang : Media Kita.

[9] Edhy Sutanta. 2004. Sistem Basis Data. Yogyakarta : Graha Ilmu.

[10] Efendi, B.E. 1989. Dbase. Yogyakarta : Andi.

[11]Eka Putra, Geri. 2015. Perancangan alat ukur tinggi badan dan berat badan menggunakan arduino uno r3, microsoft visual studio dan microsoft sql server 2008 untuk pembuatan surat keterangan berbadan sehat, STTPayakumbuh.

[12] Gordon Mcleod, Jr .2001 . Sistem Informasi. Jakarta : Prenhallindo.

[13]Ian, Robertson. Elektronika Digital. 2001. Jakarta: PT. Elekmedia Komputindo.

[14] Jogianto, HM.2002. Pengenalan Komputer.Yogyakarta: Adi Offset.

[15] Jusak. 2013. "Implementasi Zigbee Ieee 802.15.4 Untuk Pemantauan Suhu Dan Kelembaban Udara." SNASTI. Retrieved (http://sir.stikom.edu/556/1/2013-ICCS-21.pdf

[16] Julien Bayle. 2013. C Programming for Arduino. Birmingham B3 2PB, UK: Packt Publishing Ltd. Retrieved (http://books.google.com.my/books?id=AfNV215sPAC\&lpg=PA1\&pg=PA20\#v=onep age \&q\&f=false)

[17] Jatmika, Yusep Nur. 2011. cara mudah merakit robot untuk pemula. edited by Putri Erine Nareswati. Yogyakarta: FlashBooks.

[18] Kadir, Abdul.2009. Arduino. Yogyakarta : Andi. 
[19]Lovedy, George.2001. IntisariElektronika. Gramedia Jakarta: PT Alex Media Komputindo.

[20] Malvino, Hanapi Gunawan.2001. Prinsip Prinsip Elektronika. Jakarta Erlangga.

[21] Noviardi, 2016. Aplikasi Serial Komunikasi Arduino Uno R3, Vb.Net 2012 dan SQL Server 2008, jurnal elektro ITP. ISSN.2252-3472, vol : 1 Tahun 2016.

[22] Putra, Agfianto Eko. 2002. Teknik Antarmuka Komputer : Konsep dan Aplikasi. Edisi Pertama. Yogyakarta: Graha Ilmu.

[23] Ramon A.Mata-Taledo, Ph.D. 1999. Dasar dasar Database Relasional. Jakarta : Erlangga.

[24] Ridwan Sanjaya, SE, S.Kom. 2004. MySQL4. Yogyakarta : Andi.

[25] Roy Rarry. 2012. Jurus Kilat Mahir. Jakarta Timur : Dunia Komputer.

[26] Robles, Tomás et al. 2015. "An IoT Based Reference Architecture for Smart Water Management Processes." Journal of Wireless Mobile Networks, Ubiquitous Computing, and Dependable Applications (JoWUA) 6(1):4-23

[27] Sugiono. 2009. "Mudah Mengerjakan Skripsi, Thesis Dan Disertasi."

[28] Sugiri, A. Md., S. Pd. 2004. Elektronika Dasar \& Peripheral Komputer. Andi Offset Yogyakarta.

[29] Wiranto Herry Utomo. 2010. Pemodelan BasisData Berorientasi Objek. Yogyakarta : Andi.

[30]Zaki, M. H., 2005, “Cara Mudah Belajar Merangkai Elektronika Dasar”, Yogyakarta, Absolut. 